\title{
Etiology, Epidemiological Aspects and Preventive Strategies of Neural Tube Defects
}

\author{
Rabindran $^{1 *}$, Shasidaran $^{2}$
}

${ }^{1}$ Consultant, Neonatologist, Billroth Hospital, Chennai, India

${ }^{2}$ Senior Resident, Department of Radiology, S.R.M. Medical College and Research Centre, Chennai, India

DOI: $10.36347 /$ sjams.2020.v08i09.031

| Received: 13.09.2020 | Accepted: 21.09.2020 | Published: 24.09.2020

*Corresponding author: Rabindran

Abstract

Review Article

Neural tube defect (NTD) is a defect in neurulation process of embryogenesis occuring during early human development. Failure of normal closure of neural tube causes NDT. Type and severity varies based on location of defect. NDT occurs predominantly at rostral and caudal ends. Folate is essential for DNA and RNA synthesis and for one carbon group transfer in methylation and nucleic acid synthesis. In folate deficiency, there is failure of posttranslational methylation of the cytoskeleton leading to NTD. Some of the contributing factors for NTD include maternal illness, Low socio-economic status, Drugs, Food contamination and maternal Smoking. Folic acid supplementation reduces the prevalence of NTD by 70\%. Multiple genes are associated with folate insensitive NTD. NTD can be classified based on the site of defect into Cranial and Spinal malformations and based on the presence or absence of exposed neural tissue into open or closed types. Some of the common factors to be considered in analysing NTD include Multiple Gestation, Dietary Factors, Sex, and Maternal obesity, Illness, Age, Socioeconomic Status, Parity, Occupational Exposure and Previous Pregnancy Wastage. Most popular strategy for prevention of NTD is folic acid supplementation for women of childbearing age. Other strategies for prevention of NTD include folate-rich diet, multivitamin supplementation, 6S- 5-MTHF, food fortification, combination of oral contraceptives and folate. With recent advances in genetics and diagnostic tools, genetic and syndromic causes of NTD can be prevented utilizing preimplantation genetic diagnosis or early detection by chorionic villous sampling and high resolution early antenatal ultrasound scan.

Keywords: Neural Tube Defect, Folate Supplementation, Homocysteine.

Copyright @ 2020: This is an open-access article distributed under the terms of the Creative Commons Attribution license which permits unrestricted use, distribution, and reproduction in any medium for non-commercial use (NonCommercial, or CC-BY-NC) provided the original author and source are credited.

\section{INTRODUCTION}

Neural tube defects (NTD) are developmental defects which occur in early human development during $3^{\text {rd }}$ week of pregnancy at the gastrulation stage [1]. It is a defect in neurulation process of embryogenesis [2]. Normally cells on dorsal side of embryo undergo change to form neural tube. Failure of normal closure of neural tube causes an opening in cranium or spine, which is called as NDT. Type and severity varies based on location of the defect. NDT occurs predominantly at rostral and caudal ends because during the process of neurulation, neuropore closure occurs at the last at rostral and caudal ends [3].

\section{Etiology}

Humans cannot produce folate. Dietary sources of folate include fresh and frozen green leafy vegetables, citrus fruits and juices, liver, wheat bread and legumes such as beans. Folate is essential for DNA and RNA synthesis. It is also important in one carbon group transfer in methylation and nucleic acid synthesis. In folate deficiency, there is failure of posttranslational methylation of the cytoskeleton leading to poor differentiation which leads to NTD. Early human embryo is vulnerable to folate deficiency due to difference of the functional enzymes during embryogenesis along with high demand for post translational methylations of the cytoskeleton in neural cells during neural tube closure [4].

There are numerous genetic syndromes associated with NTD [5]. The specific genes involved are being studied. NTD have been identified in genetic syndromes with various modes of inheritance. Majority are Chromosomal disorders. Among single gene defects, most of genetic syndromes with NTD have autosomal recessive inheritance. Autosomal dominant and sex linked inheritance have also been noticed in some syndromes [6]. 


\begin{tabular}{|c|c|c|}
\hline \multicolumn{3}{|c|}{ There are many contributing factors of NTD which include } \\
\hline Folate Deficiency & Maternal Diabetes & Low Socio-Economic Status \\
\hline Drugs & Maternal Hyperthermia & \\
\hline & Maternal Stress & $\begin{array}{l}\text { Food contaminated with Fumonisins } \\
\text { (Myocotoxins) }\end{array}$ \\
\hline Pesticides & Maternal Smoking & \\
\hline Hazardous waste & Maternal Diarrhea & Electromagnetic fields \\
\hline & Maternal Dieting Behavior & \\
\hline $\begin{array}{l}\text { Chlorination disinfection by-products } \\
\text { in drinking water }\end{array}$ & $\begin{array}{l}\text { Maternal intake of foods with high } \\
\text { Glycemic Index }\end{array}$ & $\begin{array}{l}\text { UV Radiation-induced Folate } \\
\text { Photolysis }\end{array}$ \\
\hline
\end{tabular}

Some of the drugs which are suspected to cause NTD include antihistamines, sulphonamides, anticonvulsants, carbamazepine, valproate, methotrexate and aminopterin, recently research has suggested association between NTD and Maternal myoinositol, zinc and glucose levels. Folic acid supplementation has shown to have reduced the prevalence of NTD by 70\% [7]. However there are some NTD which occur independent of folate levels. Multiple genes are found to be associated with folate insensitive NTD. Meckel syndrome and Triploid Syndrome have NTD which is suspected to be unrelated to folate metabolism [5].

\section{Types of NTD}

NTD can be classified based on the site of defect and based on the presence or absence of exposed neural tissue. Based on the site of defect there can be Cranial and Spinal malformations [8].

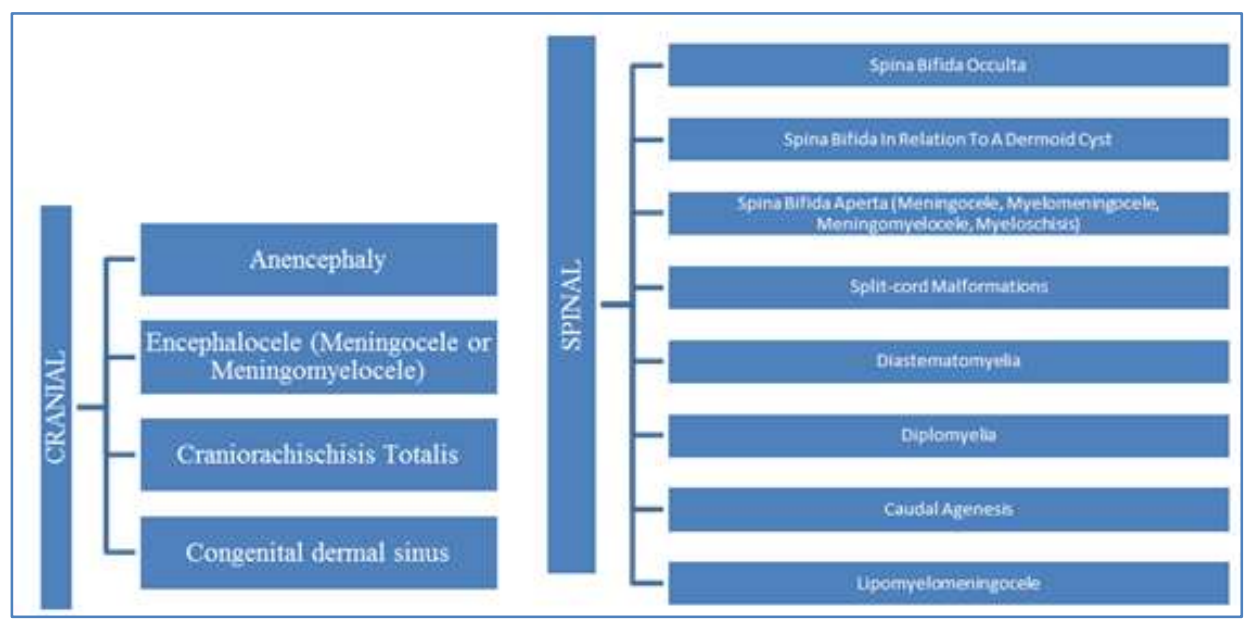

Based on the presence or absence of exposed neural tissue, NTD can be classified as "open" or "closed" types.

\begin{tabular}{|ll|}
\hline OPEN NTD & CLOSED NTD \\
\hline$\square$ Meningocele (Spina Bifida) & $\square$ Lipomyelomeningocele, \\
$\square$ Myelomeningocele & $\square$ Lipomeningocele \\
$\square$ Encephalocele & $\square$ Tethered cord \\
$\square$ Anencephaly & \\
\hline
\end{tabular}

Open NTD are the commonest and they constitute about $80 \%$ of all NTD. Open NTD occur due to failure of primary neurulation. Neural tissue is exposed or covered by a membrane. There may be cerebrospinal fluid (CSF) leakage [9]. They are associated with presence of Hydrocephalus and Chiari II malformation. In contrast, Closed NTD are localized and confined to spine. They occur due to failure in secondary neurulation. There is no neural tissue exposure and defect is fully covered by epithelium [10].

\section{Epidemiological Aspects of Neural Tube Defects \\ Prevalence of NTD is dependent on}

epidemiological, demographic and social factors. Some of the common factors to be considered in analysing NTD include. 


\begin{tabular}{|l|l|l|}
\hline Variations in Birth Incidence & Multiple Gestation & Dietary Factors \\
\hline Sex & Obesity & Recurrence of NTD \\
\hline Age of Presentation & Maternal Illness & Family Recurrence Risks \\
\hline Maternal Age & Socioeconomic Status & Folate and NTD \\
\hline Parity & Occupational Exposure & Genetics and NTD \\
\hline Previous Pregnancy Wastage & \multicolumn{2}{|l}{} \\
\cline { 2 - 3 }
\end{tabular}

\section{Variations in Birth Incidence}

There is seasonal and secular variations noted in the trend of prevalence of NTD. Some of the etiological factors leading to NTD are common at specific prenatal age. According to Indian data, the estimated prevalence of NTD varies between 0.5 to 11 per 1000 births [1]. Studies from the time before inutero diagnosis and termination of affected pregnancies has established two trends. Initially there were epidemics of NTD followed by a general decline over several decades. Racial data suggest significance of genetic component in occurence of NTD [11].

\section{Sex}

Among NTD, cranial defects are more common in female. For example, Anencephaly has a female-to-male ratio of 3:1. Likewise other NTD which arise from regions above thoracolumbar junction show female preponderance [12]. However in case of distal forms of spina bifida, there is no such gender bias. The explanation for such female predisposition is that the requirement of human chorionic gonadotropin is more in female fetus as compared to male. This hormone deficiency can increase the risk of NTD [13].

\section{Age of presentation}

The time at which the NTD are detected varies based on the type. Since there is exposed neural tissue along with CSF leak sometimes, open NTD are immediately diagnosed at birth. In fact antenatal scans can pick some of such defects. Moreover presence of associated Hydrocephalus or Chiari II malformation helps in early diagnosis. In contrast, closed NTD may remain undiagnosed even for decades. This is more possible in the absence of cutaneous markers. However, one or more cutaneous lesions are present in nearly $70 \%$ of asymptomatic patients with closed NTD.

\section{Maternal age}

Per se maternal age does not directly affect incidence of NTD. However in presence of other risk factors, risk for NTD increases in older and very young mothers [14].

\section{Parity}

Compared to maternal age, parity has a stronger association with NTD risk. Primiparous mothers are at increased risk and there is a modest risk in mothers of parity three or more [15].However there is no association between the risk of NTD and infertility treatment [16].

\section{Previous Pregnancy Wastage}

Previous spontaneous abortions increase the risk of subsequent development of NTD [17]. Short interval between pregnancies also contributes to occurrence of NTD [18].

\section{Multiple Gestations}

Association between NTD and multiple gestations is complex. Twinning itself has been associated with a higher risk for NTD [19].

\section{Obesity}

Increase in Maternal weight and elevated body mass index have been associated with increased risk for NTD. When the Body mass index is more than 29 , the risk for NTD doubles [20].

\section{Maternal illness}

Maternal health affects the fetus. In case of NTD also maternal illnesses, maternal diabetes, maternal hyperthermia have been associated with increased risk for NTD. First trimester of pregnancy is very important. A flu or cold syndrome, febrile illness or Hot-tub use in the first trimester has been associated with a 2-3 fold higher risk for occurrence of NTD [21]. The combination of hottub use, febrile illness and sauna use increases the risk of NTD six fold.

\section{Parental Socioeconomic Status}

The socio-economic status of the family determines the nutrition and wellbeing of the family. Lower socio-economic status is associated with higher incidence of NTD [22].

\section{Parental Occupational Exposures}

Some parental occupations have increased risk for NTD. For example increased risk of NTD is associated with both paternal and maternal occupations like welding, transport, painting, cleaning, healthcare occupations and agriculture [23].

\section{Dietary Factors and Other Exposures}

Proper diet during pregnancy is very important for a healthy baby. Excessive intake of Tea during the first trimester has a twofold increased risk of NTD [24]. Excess vitamin A, Lead exposure, Zinc deficiency and high levels of organic matter in drinking water are associated with higher NTD occurrence [25]. Cigarette smoking causes elevations of homocysteine levels and increased risk of NTD [26]. 


\section{Recurrence of NTD}

Recurrence rate of NTD triples with each subsequent pregnancy after the first affected pregnancy. The recurrence risk of NTD after one affected pregnancy is around $4 \%$, whereas it is $11.1 \%$ after two affected pregnancies and about $28.6 \%$ after three affected pregnancies [15].

\section{Family Recurrence Risks}

Consanguinity increases the occurrence of many diseases and genetic disorders. For first-degree relatives of affected individuals the risk of NTD is approximately 1 in 30 . For second-degree relatives, the risk is approximately 1 in 220 [27].

\section{Folate and NTD}

Normally during protein metabolism, amino acids like methionine are released. Methionine is converted to a toxic metabolite. Remethylation of homocysteine to methionine is catalyzed by methionine synthase enzyme which requires vitamin B12 as a cofactor and 5-Methyl-tetra-hydro-folate (5-MTHF) as methyl donor. Hence folate deficiency can lead to accumulation of toxic homocysteine and thereby leads to defects like NTD.

\section{Genetics and NTD}

Genetic polymorphism of MTHFR - (Methyltetra-hydro-folate reductase) gene is the important cause of hyperhomocysteinemia and/or lack of methionine. MTHFR: c.677C $1 \mathrm{~T}$ mutation reduces activity of MTHFR enzyme which causes decreased 5-MTHF production [28]. Since 5-MTHFis the methyl donor for remethylation of homocysteine to methionine, its deficiency leads to increased homocysteine level and decreased methionine levels [29]. These cause delay in the neural tube closure and NTD.

\section{Prevention of NTD}

NTD are defects that occur in early human development. Hence prevention of NTD revolves mainly in the antenatal period. Most popular strategy is folic acid supplementation for women of childbearing age. The following are some of the strategies for prevention of NTD

\section{Consumption of Folate-Rich Diet}

About 3.5 fold increase in daily folate intake $(0.16-0.20 \mathrm{mg} / \mathrm{day})$ is required prior to conception. Moreover Cooking reduces some part of dietary folate. Hence folate rich diet is important for NTD prevention but cannot alone neutralize genetic predisposition [30].

\section{Periconceptional Folate Supplementation}

Since dietary supplementation is difficult, all women of childbearing age should take $400 \mathrm{mcg}$ of folic acid daily atleast three months prior to anticipate pregnancy. Those with previous child with NTD should increase dose to $4.0 \mathrm{mg}$ daily [31]. If maternal intake of folic acid can be increased around the time of conception, the risk of the occurrence of NTD may be reduced by $60-70 \%$ [7].

\section{Multivitamin Supplementation}

Folic acid supplementation can reduce the prevalence of NTD by $70 \%$. However there are some NTD which occur independent of folate levels. They occur due to defects in folate-homocysteine metabolism for homocysteine detoxication due to deficiency of cofactors like vitamins B12, B2 and B6. Hence folate and Vitamin B12, B2 and B6 containing multivitamins are more effective in prevention of NTD [32].

\section{S- 5-MTHF}

6S-5-MTHF is a nature-identical folate .Thus inspite of being a synthetic product, it is equivalent to the natural form [33].

\section{Food Fortification}

Since majority of pregnancies are unplanned, food fortification is the most practical means of folate supplementation. Food fortification with folic acid of cereals about $0.14 \mathrm{mg} / 100 \mathrm{~g}$ adds only $0.1 \mathrm{mg}$ folic acid to daily folate intake, however there was around $26 \%$ decreased in total (birth + fetal) prevalence of NTD [34].

\section{Combination of Oral Contraceptives and Folate}

There is now a FDA approved drug combining drospirenone and ethinyl estradiol as contraceptive components and levomefolate calcium as folate component [35].

\section{Managing Pre-Existing Health Conditions}

Since maternal illness and premorbid conditions are a risk factor for occurence of NTD, preventing diabetes by monitoring blood sugar levels and preventing Obesity can help in prevention of NTD. Expectant mothers must be protected against infections, fever should be treated promptly and any environmental exposures that increase core body temperature should be limited as hyperthermia is a risk factor for occurrence of NTD. Medications like antihistamines, sulphonamides, anticonvulsants, carbamazepine, valproate, methotrexate and aminopterin should be avoided during pregnancy [36]. With recent advances in genetics and diagnostic tools, genetic and syndromic causes of NTD can be prevented utilizing preimplantation genetic diagnosis (PGD) or early detection by chorionic villous sampling and high resolution early antenatal ultrasound scan.

\section{Conclusion}

Neural tube defect is a defect of early human development. Understanding the etiological factors and contributing epidemiological factors will help in reducing the prevalence of NTD. Inspite of advances in diagnosis, even though defects in fetus can be diagnosed early and termination can be done, preventing NTD by judicious folate supplementation 
and avoiding risk factors can really reduce prevalence of NTD. As always prevention is better than cure.

\section{REFERENCE}

1. Singh V, Raina S, Dewan D, Raina S, Dogra V. Epidemiological study of neural tube defects in Jammu division, India. Int J Res Med Sci. 2019; 7:682-6.

2. Tamura T, Picciano MF. Folate and human reproduction. The American journal of clinical nutrition. 2006 May 1;83(5):993-1016.

3. Dirks PB, Rutka JT. The neurogenetic basis of pediatric neurosurgical conditions. In: Albright L, Pollack I, Adelson D, eds. Principles and Practice of Neurosurgery. New York: Thieme Medical Publishers; 1999: 23-4.

4. Bjorklund NK, Gordon R. A hypothesis linking low folate intake to neural tube defects due to failure of post-translation methylations of the cytoskeleton. International Journal of Developmental Biology. 2003 Jan 1;50(2-3):13541.

5. Rose, N, Mennuti, M, Glob. Fetal Neural Tube Defects: Diagnosis, Management, and Treatment libr. women's med. 2009;

6. Pulikkunnel ST, Thomas SV. Neural tube defects: pathogenesis and folate metabolism. JAPI. 2005 Feb;53:127-35.

7. Blencowe H, Cousens S, Modell B, Lawn J. Folic acid to reduce neonatal mortality from neural tube disorders. International journal of epidemiology. 2010 Apr 1;39(suppl_1):i110-21.

8. Molloy AM. The role of folic acid in the prevention of neural tube defects. Trends in food science \& technology. 2005 Jun 1;16(6-7):241-5.

9. Harris LW, Oakes WJ. Open neural tube defects. In: Tindall GT,Cooper PR, Barrow DL, eds. The Practice of Neurosurgery. Baltimore: Williams \& Wilkins. 1996: 2779-89.

10. McComb JG, Chen TC. Closed spinal neural tube defects. The Practice of Neurosurgery. 1996:275477.

11. Roberts CJ, Lowe CR. Where have all the conceptions gone?. InProblems of birth defects. 1975: 148-150. Springer, Dordrecht.

12. Farhud DD, Hadavi V, Sadighi H. Epidemiology of neural tube defects in the world and Iran. Iranian journal of public health. 2000:83-90.

13. Janerich DT. Female excess in anencephaly and spina bifida: possible gestational influences. American journal of epidemiology. 1975 Jan 1;101(1):70-6.

14. Fujimori E, Baldino CF, Sato AP, Borges AL, Gomes MN. Prevalence and spatial distribution of neural tube defects in São Paulo State, Brazil, before and after folic acid flour fortification. Cadernos de saude publica. 2013 Jan;29(1):145-54.

15. Little J, Elwood JH. Epidemiology and control of neural tube defects. Oxford University Press, USA; 1992.
16. Mills JL, Hoffman H, Simpson JL, Rhoads GG, Graubard BI, Conley MR, Lassman M, Cunningham G. Risk of neural tube defects in relation to maternal fertility and fertility drug use. The Lancet. 1990 Jul 14;336(8707):103-4.

17. Canfield MA, Annegers JF, Brender JD, Cooper SP, Greenberg F. Hispanic origin and neural tube defects in Houston/Harris County, Texas: II. Risk factors. American journal of epidemiology. 1996 Jan 1;143(1):12-24.

18. Todoroff K, Shaw GM. Prior spontaneous abortion, prior elective termination, interpregnancy interval, and risk of neural tube defects. American journal of epidemiology. 2000 Mar 1;151(5):505-11.

19. Windham GC, Bjerkedal T. Malformations in twins and their siblings, Norway, 1967-79. Acta geneticae medicae et gemellologiae: twin research. 1984 Jan;33(1):87-95.

20. Hendricks KA, Nuno OM, Suarez L, Larsen R. Effects of hyperinsulinemia and obesity on risk of neural tube defects among Mexican Americans. Epidemiology. 2001 Nov 1:630-5.

21. Shaw GM, Todoroff K, Velie EM, Lammer EJ. Maternal illness, including fever, and medication use as risk factors for neural tube defects. Teratology. 1998 Jan;57(1):1-7.

22. Frey L, Hauser WA. Epidemiology of neural tube defects. Epilepsia. 2003 Jun;44:4-13.

23. Brender J, Suarez L, Hendricks K, Baetz RA, Larsen R. Parental occupation and neural tube defect-affected pregnancies among Mexican Americans. Journal of occupational and environmental medicine. 2002 Jul 1;44(7):650-6.

24. Correa A, Stolley A, Liu Y. Prenatal tea consumption and risks of anencephaly and spina bifida. Annals of epidemiology. 2000 Oct 1;10(7):476-7.

25. Hwang BF, Magnus P, Jaakkola JJ. Risk of specific birth defects in relation to chlorination and the amount of natural organic matter in the water supply. American Journal of Epidemiology. 2002 Aug 15;156(4):374-82.

26. Meng X, Sun Y, Duan W, Jia C. Meta-analysis of the association of maternal smoking and passive smoking during pregnancy with neural tube defects. International journal of gynaecology and obstetrics: the official organ of the International Federation of Gynaecology and Obstetrics. 2017 Oct 23;140(1):18-25.

27. Toriello HV, Higgins JV, Opitz JM. Occurrence of neural tube defects among first-, second-, and third- degree relatives of probands: Results of a United States study. American Journal of Medical Genetics. 1983 Aug;15(4):601-6.

28. Yan L, Zhao L, Long Y, Zou P, Ji G, Gu A, Zhao P. Association of the maternal MTHFR C677T polymorphism with susceptibility to neural tube defects in offsprings: evidence from 25 casecontrol studies. PLoS One. 2012 Oct 3;7(10):e41689. 
29. Akchiche N, Bossenmeyer- Pourié C, Kerek R, Martin N, Pourié G, Koziel V, Helle D, Alberto JM, Ortiou S, Camadro JM, Léger T. Homocysteinylation of neuronal proteins contributes to folate deficiency- associated alterations of differentiation, vesicular transport, and plasticity in hippocampal neuronal cells. The FASEB Journal. 2012 Oct;26(10):3980-92.

30. Greene ND, Stanier P, Copp AJ. Genetics of human neural tube defects. Human molecular genetics. 2009 Oct 15;18(R2):R113-29.

31. Houk VN, Oakley GP, Erickson JD, Mulinare J, James LM. Recommendations for the use of folic acid to reduce the number of cases of spina bifida and other neural tube defects.Centers for Disease Control. Morbidity and Mortality Weekly Report. 41 (RR-14): 001.

32. Li F, Watkins D, Rosenblatt DS. Vitamin B12 and birth defects. Molecular genetics and metabolism. 2009 Oct 1;98(1-2):166-72.

33. Wright AJ, King MJ, Finglas PM. Folatesupplemented oral contraceptives: does 6S-5- methytetrahydrofolic acid (Metafolin $®$ ) offer advantages over folic acid. InGynaecol Forum. 2010; 15: 29-32).

34. Leonor Maria Pacheco Santos, Roberto Carlos Reyes Lecca, Juan Jose Cortez-Escalante, Mauro Niskier Sanchez Humberto Gabriel Rodrigues. Prevention of neural tube defects by the fortification of flour with folic acid: a populationbased retrospective study in Brazil. Bulletin of the World Health Organization. 2016;94:22-29.

35. Holzgreve W. Adding folate to the pill to prevent neural tube defects. InGynaecol. Forum. 2010; 15: 4-8.

36. Suarez L, Brender JD, Langlois PH, Zhan FB, Moody K. "Pregnant women taking medication for epilepsy have a higher chance of having a child with a neural tube defect. Maternal exposures to hazardous waste sites and industrial facilities and risk of neural tube defects in offspring". Annals of Epidemiology. 2007;17(10): 772-77. 